\title{
Conservation and Livelihood Conflict of Kaziranga National Park: A World Heritage Site of Assam, India
}

Arup Kumar Hazarika ${ }^{+*}$ and Unmilan Kalita ${ }^{¥}$

\section{Abstract}

The conservation history of Kaziranga National Park has traversed many a path since it was first recognised as a 'game sanctuary' in 1916. The unique aesthetics and richness of its biodiversity, severely afflicted by natural and anthropogenic interventions now and then, has necessitated conservation of this wildlife reserve. An outcome of the conservation process pertains to disruptions in livelihood of the local communities, that have for generations, used the park's natural resources and therefore, had become a part of its natural evolution. Hundreds of people have lost their livelihoods and violent confrontations have become a typical scene, with the communities being utterly left out of the conservation process. In this light, the present essay envisages discussing the centrality of community participation in the conservation of Kaziranga National Park vis-à-vis a conjugation of the conservation process and livelihood aspirations of the local people.

Keywords: Kaziranga National Park; Conservation; Livelihood; Biodiversity; Eco-tourism; Assam; India

\footnotetext{
${ }^{+}$Department of Zoology, Cotton University, Assam, India

${ }^{*}$ Coresponding Author, Email: chiefeditorclarion@gmail.com

¥Department of Economics, Gauhati University, Assam, India, Email: unmilan.k@gmail.com

(C) 2019 Hazarika \& Kalita. This is an Open Access article distributed under the terms of the Creative Commons Attribution License (http://creativecommons.org/licenses/by/2.0), which permits unrestricted use, distribution, and reproduction in any medium, provided the original work is properly cited.
} 


\section{Introduction}

An environment with a resounding species diversity reinforces economic stability and human livelihoods over time (Janishevski et al., 2008). With unabated destruction and desertification of forests and consequent species extinction, the potential of protected areas and national parks as proven mechanisms for conservation of biological diversity and associated livelihoods has gained traction globally. The Kaziranga National Park (KNP), considered an embodiment of biodiversity and ecosystem services, is one of the seven natural World Heritage Sites of India, inscribed for being the 'world's major stronghold of the Indian onehorned rhino', currently with a species strength of two-thirds of the global rhino population. Severely affected by fluvial processes and bank erosion, coupled with negative anthropogenic interventions, KNP has suffered from deaths of numerous wildlife species, destruction of ecosystems and discontinuity in ecological successions, time and again. As such, the conservation process of KNP hovers around strictly protecting its biodiversity and negating human interventions. It is no secret that poaching of rhino horns has been notoriously active in and around the park, and efforts to contain it has faced dead-ends. The strict conservation process has now and then devoid fringe communities of their livelihood as well as their traditional lands, subsequently resulting in clashes among park authorities and local people. This brings to the fore the question whether a conservation process will be successful on its own without acknowledging the livelihood aspirations and traditional wisdom of local communities.

The article begins with a brief description of the biodiversity of KNP. Following this, we critically discuss the issues of conservation of KNP and the emergent livelihood conflict and its associated economics. In the final section, we discuss the strategies for reconciliation of conservation process and livelihood status.

\section{Biodiversity of KNP}

KNP is located in the state of Assam, in the northeastern part of India. It covers an area of 430 square kilometres, extending over the districts of Golaghat, Karbi Anglong and Nagaon, along the latitude of $26040^{\prime} \mathrm{N}$ and the longitude of $93042^{\prime}$ E. The vegetation of KNP extends from tropical semi-evergreen forests and mixed deciduous forests to alluvial savanna woodlands and inundated grasslands. Its faunal diversity comprises of 2,431 (Rhino Census, 2018) rhinos, a large population of elephants $(1,940)$, Asian water buffalos $(1,666)$ and tigers $(104)$ along with others such as Indian and Chinese pangolins, Assamese Macaque, Golden Langur, Capped Langur, Bengal slow loris and the famous Hoolock Gibbon, the only ape found in India. The critically endangered Gangetic dolphin also traverses the waters of the park. KNP earlier had a privilege of hosting the International Union for Conservation of Nature (IUCN) Red Listed critically endangered pygmy hog, which is no longer found here. Birdlife International has declared KNP as an "Important Bird Area" (IBA) as it famously hosts several rare and endangered species, such as the Swamp Francolin, Bengal Florican, Great Indian Hornbill, Bristled Grassbird, and so on. The park is also the abode to a large number of migratory bird species that include Lesser and Greater Adjutant Stork, BlackNecked Stork and Asian Openbills. The park earlier held the pride of hosting seven species of vultures, which it lost as the vulture population almost reached extinction due to exposure to the drug Diclofenac and other conservation failures. At present, the Red-headed Vulture, Griffon Vulture, Himalayan Griffon and Eurasian Black Vulture could be seen in the wild but are near threatened, with others already extinct in the wilderness of KNP.

\section{The Necessity of Conservation and its Status in KNP}

The conservation efforts of KNP as a protected area bears incredible significance in terms of preserving the indigenous biological diversity and halting the ongoing crisis of extinction, while playing a pivot role in creating avenues of 
livelihood for the local people. Earlier famous as a game reserve, the conservation process of KNP began in 1908. Killing animals for sport and exploitation of natural resources of the park was prohibited. KNP was crowned a Wildlife Sanctuary in 1950 and was eventually declared a national park in 1974. UNESCO recognised it as a World Heritage Site in 1985. Later, KNP was given 'maximum protection under Indian conditions' at all levels of administration under the Biodiversity Conservation Act, 2002, and was segregated according to zones and conservation strategies were applied (Mathur et al., 2005). Timber harvesting and use of forest produce were banned for local people as conservation efforts took a strict turn (Das, 2017). Despite this, official reports and relevant studies suggested the death of around 567 rhinos between 1980 and 2005 due to poaching, with their regeneration rate on a declining trend (Mathur et al., 2007). Over the years, the antipoaching network has been effectively strengthened with more than 200 monitoring camps spread across KNP which includes floating camps as well. An outcome of the conservation efforts was positively witnessed when the latest rhino count was observed to be 2,413 , an increase of a dozen rhinos since the last 2015 census. It is imperative to mention here that in 1905, Indian rhinos were merely 75 .

The necessity of conservation stems from changes that have occurred in and around Kaziranga over the years. For instance, more than 20 villages and at least four tea estates border KNP. The Karbi plateau adjoins the park, lying on its southern side. As such, the total population in the immediate area of the park is more than 70,000 (Mathur et al., 2007). Landuse changes have been continually observed wherein open areas have been converted into tea gardens while creating settlements or conducting jhum cultivation. Pesticide run-off from the tea gardens threatens the park's biodiversity by accelerating the growth of invasive species. It must be noted that pesticide run-off is challenging to control and has enormous chances of entering the food chains in KNP.
Additionally, oil exploration in facilities such as the Numaligarh refinery has caused contamination in the upstream part of the rivers flowing through KNP. Moreover, wildlife occasionally treads near human settlements and agricultural fields due to their proximity to the park. Threats of these sorts have made it imperative to conserve KNP and its natural values so that they are not lost to development processes.

\section{The Conservation and Livelihood Conflict}

During the conversion of KNP to a protected area, the 'conventional and exclusionary topdown approach applied at Yellowstone' was put in use (Andrade and Rhodes, 2012). Such an approach suffers from the ailment of failing to factor in the participation of local people as part of the conservation process. Time and again, it has been witnessed that excluding fringedwellers from the conservation process amounts to ignoring their livelihood aspirations and traditional ways of living, which makes it difficult to enforce conservation strategies. For instance, during conservation of the Andaman coast of Thailand, a marine protected area (MNP), negative impact of the planning process was witnessed on the fishermen community, and a problematic relationship flared up between them and the park authorities (Bennett and Dearden, 2014). There was a perceived impact on livelihoods resulting from negligible tourism benefits and lack of political and physical support for development of cultural and social aspirations as well as human development. In another instance of the Hoang Lien National Park of Vietnam, local people were involved in cardamom cultivation which was mainly located in the core zone of the park. After the conservation process was started, they were forbidden from accessing most of those areas and as such, lost numerous livelihood avenues (Thuy, 2014). It had earlier been observed that cardamom cultivation and the conservation process was interlinked since cardamom plants needed large trees for shading and households cultivating the spice made an effort to maintain them. Moreover, they took extra effort in preventing and extinguishing forest fires as they 
had to save their cultivated areas. As such, fringe dwellers had invariably participated in the conservation process long before it had started.

Declaration of KNP as a protected area under the Wildlife Act, 1972, forbade the fringe communities from extracting natural resources that were traditionally crucial for their livelihoods. In some instances, traditionally dwelling communities were ruthlessly evicted from their lands, with inadequate compensation and little consultation, so that the park could be extended and the conservation process could be enlarged. Disruption of traditional ways of living can trigger unwanted adverse impacts on local communities (Garcia-Frapolli et al., 2009) which are tantamount to the poaching of wildlife within the park. Local communities around KNP have over the years tried to resist laws and strategies implemented for protection of the park 'because of a fear psychosis' (Das, 2017). There is a consensus among the villagers regarding the fear of losing lands and income sources to the conservation process. It is important to note here that these people entertain the thought of supporting the process if they receive assurance of economic benefits and some form of rural development, as an outcome. This aspect of conservation can be amplified using an example of Kandhulimari village, located in KNP's Agoratoli range. Given the village's proximity to the park, animals have over the years ravaged its crops and killing livestock, inhibiting the growth of their only means of livelihood. Not having received much support from the authorities for rehabilitation, the entire village decided to set up a resort so as to target a tourism-based livelihood avenue, without any government financing support. Later, an Assam Industrial Corporation project for tourism development was sanctioned to be set up near Kandhulimari which would have its own lodging and safari activities for tourists. This had caused resentment amongst the villagers since tourists would expectedly prefer to stay in a government facility rather than one owned by a village community. This example bears the signature of a gross policy mismatch. Besides, in 2016, areas under the villages of Bandardubi, Palkhowa and Deuchurnchang were cleared for addition to the park as its seventh and eighth additions. The administration evicted 168 families from Bandardubi, 115 families from Deuchurnchang and 12 families from Palkhowa. It had been reported that the district administration had to use force to disperse mobs of villagers during the eviction drive and two persons were killed as a result. Amongst such chaotic interventions, whether the authorities and policymakers helming the conservation process have factored in destruction of local livelihoods, as both the cause and consequence of poaching, has remained utterly dubious.

\section{The Economics of Livelihood and KNP}

Where environment and humanity converge, a phenomenon termed as 'the hidden harvest' exists. It pertains to the 'diversity of goods provided freely from the environment- from non-cultivated ecosystems such as natural forests, woodlands, wetlands, lakes, rivers and grasslands' (Angelsen et al., 2014: S13). This bears immense significance in case of KNP as local households heavily depend on the park to meet subsistence needs and also earn income. To understand the relationship between the livelihood of local people and the conservation process of KNP, this essay finds it imperative to discuss the socio-economic and demographic characteristics of the people and the centrality of KNP in their livelihood aspirations.

The population profile of fringe villages of the KNP comprises primarily of a middle-aged population, and the mean household sizes hover around six members (Hazarika and Anand, 2001; Borah et al., 2018). Homogeneity of household incomes vis-à-vis KNP is observed among the households due to the proximity with KNP. Educational profile of the dwellers reveals a low level of education, confined mainly to high school matriculation (Verma, 2014). Increased migration of people to the vicinity of KNP within the last two decades have been witnessed, corroborated by significant evidence of shortterm dwelling households. Variation in dwelling periods also has significant bearings upon the literacy level of the population as well as their awareness towards KNP conservation efforts, as evident from the Sundarbans region (Das, 2005). 
Social participation among different groups in the vicinity of KNP has been observed to be very low (Kutum et al., 2011). This could be attributed to the significant variation among household demographics with respect to ethnicity and religion (Shrivastava and Heinen, 2007).

Occupational profile of the local villages categorically indicates livelihood avenues to be primarily agriculture and livestock rearing, with a minority involved in other occupations (Borah et al., 2018; Das, 2017). They are immensely dependent upon KNP for acquiring natural resources and using them as inputs in agriculture or as feedstock for cattle and other livestock. Further, fishing is a major source of income for the villages. Although, prohibited in KNP, fishing is mostly carried out in the floodplains of the Brahmaputra, the Diphlu and Mora Diphlu rivers. An abundance of fish harvests is observed among the villagers with minimal spatial variations. Fishing incidence has been observed to vary with occupation but now with income (Shrivastava and Heinen, 2007). Similarly, firewood gathering is a major resource use among the villagers. This pertains to the fact that traditionally, firewood is the most used household fuel in Assam, particularly in the rural areas, and as such, forest produce is evidently crucial for the villagers. Cent per cent of these villages makes use of firewood for cooking, whereas timber and bamboo are sold in local markets. Timber products are a favourite among the tourists and can be seen locally sold at the entrance of KNP. Bamboo is considered a minor forest produce as per the Forest Rights Act (2006), but timber within the park is protected. Firewood harvest from KNP is also prohibited and most of the wood for household usage comes from the KNP transition zone or the Karbi Hills. Interestingly, it has been observed that timber felling and firewood harvesting has not reduced in KNP even though it is legally forbidden. This constitutes the ground for conflict between conservation efforts and sustainability of livelihoods.

Damage due to wildlife attacks is a significant problem associated with KNP and its neighbouring villages. Crops get ravaged by elephants and wild buffaloes while livestock is hunted by tigers. Villagers tend to chase the animals away or in some cases, attack them. Human lives have also been lost in this humananimal conflict. The spread of such damages covers almost $70 \%$ of the entire KNP vicinity and has become a significant issue. Although economic valuation of property and crop damages is not reliably available, studies cite an average cost of USD 55 and USD 69 per household respectively (Das, 2017). Greatest damages are faced by those who live in the transition zone and face costs upto INR 10,000 per attack (Mackenzie et al., 2012). To address the impacts of such losses, KNP authorities have positively initiated certain welfare measures to compensate for the damages through financial support to affected families, construction of houses, schools, community halls, fences, provision of labour support for recuperations and holding of awareness programmes, besides wildlife monitoring and resource management. However, it has been observed that such efforts from authorities have fallen short of the objectives. Fences built up for protection against crops often gets damaged by the animals because of the lack of maintenance and cooperation among both villagers and the park officials.

Moreover, very few of the affected villagers have been paid compensation against damages, the percentage is only $6.8 \%$ over the last decade. This relates to the fact that villagers have to submit pieces of evidence of crop damage due to wildlife, which is not a well thought feasible policy plan. With villagers failing to keep shreds of evidence in the way of photographs, they fail to claim compensation (Das, 2017).

The conservation process has led to greater annexation of grasslands by the KNP authorities with time. As such, people in the vicinity are facing a shortage of grazing grasslands and scarcity of fodder for their livestock. Since livestock constitutes a large part of a household's income, it is expected that a particular household will try and spend more in accumulating more livestock. There is a significant positive relation between land-use 
and profit earned due to livestock in case KNP households (Das, 2013). Corresponding with the migration taking place in the vicinity of the park, there has been a high demand for more grazing lands. Making the livestock graze in the transition zone also renders them vulnerable to animal attacks. This issue has consequently brought about several heated confrontations between the park authorities and the villagers. Moreover, the usefulness of crop protection measures in shielding crops against animal attacks has been observed. Reports, however, suggest that the park authorities or the EcoDevelopment Committee of KNP have not paid much attention in assisting the villagers in implementation of such measures.

The tourism industry of KNP is one of the most prominent avenues of income for the local communities. Despite the industry's significant scope, it has remained grossly underdeveloped and 'has not been able to adequately utilise the potential of local communities as supporters of conservation, leaving them with minimal and indirect benefits of tourism, due to enclave tourism resulting from negligible interactions between the local population and tourists' (Hussain et al., 2012: 7). Local people are involved in the industry as both direct and indirect service providers. The former relates to those having direct contact with tourists (interpreters, drivers and home-stay/lodge owners) while the latter pertains to the farmers, suppliers, labours, cottage industry workers and so on. A majority of these people had earlier been dependent on the forest's natural resources as an income source. The total income earned as part of tourism, however, still constitutes less than what villagers earn in general from agriculture and tea plantation. An essential cause of this is 'tourism leakage' which is the gap between income earned from tourism and expenditure from those earnings, by the earning individuals. The tourism leakage rate has been found to be $50 \%$ which is even higher than India's leakage rate of $40 \%$ (Hussain et al., 2012). A greater percentile of tourism leakage rests with the low-income households, since they bear a combined cost of conservation (crop losses due to wildlife damage and opportunity cost of switching to tourism) and maintenance costs (salaries to staff, capital expenditures and so on). Lack of literacy and associated soft-skill development has also impeded the potential of exploiting tourism as a livelihood avenue.

It is widely understood and of little doubt that humanity, in general, has a soft corner for the environment. This is because of the incredible aesthetics of nature, traditional and cultural values as well as the economic valuation of environment. As regards KNP, the general attitude among local villagers corresponding to its conservation process seems dependent upon several variables. For instance, it was witnessed that unfavourable attitudes were predominant among most households in the KNP vicinity (Shrivastava and Heinen, 2009) which faced loss of livelihoods due to park extension. Statistics also show that the majority of villages support biodiversity conservation in KNP (Das, 2017). Expectedly, age has not been observed to correspond to their attitude, but occupation and farm income do. Studies note that the effect of regulations impacted different communities differently and had varied repercussions. Prevalent dissatisfaction with regard to annexation of new villages and grasslands for park extension and barriers on deriving economic benefits has created discord, although most people generally agree that large mammals including the rhino, being the state symbol, should be protected.

\section{Strategy for Reconciliation of Conservation Process and Livelihood Status}

Wedding conservation and livelihood objectives are not only tricky but also unsustainable unless it is fulfilled through a 'supportive mediation process which can reconcile conflicting goals' (Thaworn et al., 2010: 29). Primarily, efforts should be made to include local communities in the decision-making process, and their opinions be given suitable importance. Their inclusion will promote a sense of ownership, making them automatically cooperate park officials in successfully fending off outsiders (poachers and encroachers) and also make an effort to regulate their exploitation of natural resources (Andrade and Rhodes, 2014). Greater community 
participation needs to be brought about through extensive awareness and orientation programmes (Reed, 2008). The importance of ecotourism as a comprehensive conservation approach is immense. Entrepreneurial efforts of local villagers have been dampened by large commercial projects. There has been lukewarm support from the government in rehabilitation of those who lost their livelihoods as part of park extensions or wildlife damages. The case of Bale Mountain National Park (BMNP) in Ethiopia bears significance in this case wherein local people are specifically involved in tour guiding, horse rental services, selling handicrafts and providing homestay services to the tourists. Deriving monetary benefits out of ecotourism has radically transformed the local community's consciousness towards sustainably using the natural resources of the park (Abacheba, 2017). Moreover, livelihood augmentation and income generation programs should be supplemented by capacity building practices so as to ensure long-term sustainability of the conservation process (Pullin and Stewart, 2006). Capacity building can be practised in terms of environmental education and resource management training, coupled with financial management and marketing courses. Focus on developing inter-sectoral linkages and livelihood diversification with respect to agriculture and artisan production should be given (Gurung and Goswami, 2015).

As regards the administrative aspect, a joint KNP Conservation Network should be formed that is to comprise of exclusively KNP authorities and local communities. Instances of such associations have been seen all across the world. Learnings from the Teen Tok Forest Conservation Network of Thailand can be taken into account wherein regulations for managing and monitoring park activities are decided on by villagers in association with the park authorities (Thaworn et al., 2010). On the other hand, villagers have voluntarily given up the freedom to organise weddings or other functions, now considered offences, and need to take permission from park rangers. They have also constituted a Forest Protection Volunteer Network comprising of youth in the village clusters and function as a ground-level force by regularly conducting forest patrols to combat poaching, watch forest fires and keep in check forest care. They, in turn, receive concessions in controlled harvesting of forest produce. At present, more than 150 villages are engaged in conservation of the protected area. Although, KNP bears a much more restricted stance than Thailand's Teen Tok, these activities can be successfully carried out in the transition zone and associated vicinities.

Another crucial factor in synchronising a conservation process to people's livelihoods is to conduct an appropriate economic valuation of the protected area using techniques of contingent valuation, revealed/stated preference and focus group discussions. This is necessary for quantifying the trade-off between costs and benefits of park authority decisions and the planning of a viable conservation process. An assessment of the willingness to pay of fringe communities for preservation of KNP will be crucial in determining the level of consciousness they have towards KNP's conservation. Preliminary investigation. Tourism leakage of KNP should be effectively addressed and local people should be made aware of its dire implications.

\section{Conclusion}

The case of KNP conservation has been the centre of varied and extensive debates vis-à-vis the environment and society. The intention of this essay was to showcase how conservation strategies cannot be rolled out as a standalone process, but only as a cooperative mechanism with local community participation as one of the pivot pillars. There is no single conservation model that can apply to all protected areas. In the context of Kaziranga National Park, confrontations have mostly risen out of economic necessities rather than political or social contexts. Most of its economics of livelihood relate to exploitation of park resources as well as poaching of the rhino horn. Needless to say, assisting people's livelihoods must not compromise the biodiversity conservation of KNP. The burning of rhino horns by concerned conservators in KNP as a mark of 
protest has indicated this. As such, the true fate of Kaziranga National Park lies in how we meticulously protect and conserve its biodiversity while critically recognising the livelihood of people associated with the park, in the conservation process.

\section{References}

Abacheba, M.A., (2017). Review on Impacts of Protected Area on Local Communities' Livelihoods in Ethiopia. Journal of Resources Development and Management, 39, pp. 8-13.

Andrade, G.S.M. and Rhodes, J., (2012). Protected Areas and Local Communities: An Inevitable Partnership toward Successful Conservation Strategies? Ecology and Society, 17(4), 14.

Angelsen, A., Pamela, J., Babigumira, R., Belcher, B., Hogarth, N. and Bauch, S., et al., (2014). Environmental Income and Rural Livelihoods: A Global-Comparative Analysis. World Development, 64, S12-S28.

Bennett, N.J. and Dearden, P., (2014). Why Local People Do Not Support Conservation: Community Perceptions of Marine Protected Area Livelihood Impacts, Governance and Management in Thailand. Marine Policy, 44, 107116.

Borah, B., Borgohain, A., Khuman, L., Dewri, R., Dutta, K., Kalita, M. and Bordoloi, G., (2018). Socio-Economic Conditions of the Fringe Villagers of Kaziranga National Park (KNP), Assam, India. International Journal of Current Microbiology and Applied Sciences, 7(5), 25302536.

Das, S. K., (2005). Livestock and Livelihood of Rural Inhabitants in Sundarbans Region of West Bengal (Doctoral Thesis). Division of Extension Education, Indian Veterinary Research Institute, Izatnagar, Uttar Pradesh.

Das, D., (2013). Problems and Prospects of Living Around Kaziranga: An Exploratory Study. International Journal of Scientific Research, 2(12), 112-114.

Das, D., (2017). Park, People and Biodiversity Conservation in Kaziranga National Park, India.
Space and Culture, 5(1), 36-47. https://doi.org/10.20896/saci.v5i1.244

Garcia-Frapolli, E., Ramos, G., Serrano, A. and Galicia, E., (2009). The Complex Reality of Biodiversity Conservation Through Natural Protected Area Policy: Three Case Studies from Yucatan Peninsula, Mexico. Land Use Policy, 26, 715-722.

Gurung, D. and Goswami, C., (2015). Developing Linkage Between Wildlife Tourism and Handicraft for Local Economic Development: A Case Study of Kaziranga National Park. Tourism and Handicraft: A Sustainable Approach (1st ed., pp. 149-158). New Delhi, Delhi: Excel India.

Hazarika, P. and Anand, U., (2001). Co-Relational Analysis of The Socio-Personal, Economic, Communication and Psychological Variables with Knowledge and Adoption Behaviour of The Dairy Farmer. Indian Journal of Social Research, 42(4), 251-255.

Hussain, S. A., Barthwal, S. and Bharadwaj, A., (2012). An Analysis of Livelihood Linkages of Tourism in Kaziranga National Park, A Natural World Heritage Site in India. PARKS, 18(2), 33-43.

Janishevski, L., Noonan-Mooney, K., Gidda, S. B., and Mulongoy, K. J. (2008). Protected Areas in Today's World: Their Values and Benefits for The Welfare of The Planet. CBD Technical Series, 36.

Kutum, A., Sarmah, R. and Hazarika, D., (2011). An Ethnobotanical Study on Missing Tribe Living in Fringe Villages of Kaziranga National Park of Assam. Indian Journal of Fundamental and Applied Life Sciences, 1 (4), 45-61.

Mackenzie, C.A., and Ahabyona, P., (2012). Elephants in the Garden: Financial and Social Costs of Crop Raiding. Ecological Economics, 75, 72-82.

Mandal, R., Barman, S. and Bezbaruah, M.P. (2014). Economic Valuation for a better Conservation: A Case Study of Kaziranga National Park, India (Issue Brief No. 14). Texas: Sam Houston State University Economics and International Business Department.

Mathur, V.B., Sinha, P.R. and Mishra, M., (2007). South Asia Technical Report on Kaziranga National Park. Paris: UNESCO. 
Mathur, V. B., Verma, A., Dudley, N., Stolton, S., Hockings, H., and James, R., (2005). Kaziranga National Park and World Heritage Site, India: Taking the Long View. In Proceedings of the 2nd World Heritage Forest Meeting (UNESCO). French National School of Forestry (ENGRE), France.

Pullin, A., and Stewart, G., (2006). Guidelines for Systematic Review in Conservation and Environmental Management. Conservation Biology, 20, 1647-1656.

Reed, M. S., (2008). Stakeholder Participation for Environmental Management: A Literature Review. Biological Conservation, 141, 24172431.

Rylance, A. and Spenceley, A., (2017). Reducing Economic Leakages from Tourism: A Value Chain Assessment of The Tourism Industry in Kasane, Botswana. Innovation and Progress in Sustainable Tourism, 17, 12-45.

Shrivastava, R. and Heinen, J. T., (2007). A Microsite Analysis of Resource Use Around Kaziranga National Park, India. The Journal of Environment and Development, 16, 207-226.

Shrivastava, R.J. and Heinen, J.T., (2009). An Analysis of Conservation Attitudes and Awareness Around Kaziranga National Park, Assam, India: Implications for Conservation and Development. Population and Environment, 30, 261-274.
Thaworn, R., Kelley, L. and Yasmi, Y., (2010). Can Biodiversity Conservation Go Hand in Hand with Local Livelihoods? A Case of Conflict Resolution in Thailand. Unasylva, 61, 28-33.

Thuy, H.N.T., (2014). Linking Rural Livelihood and Conservation in Hoang Lien National Park, Lao Cai Province, Vietnam (Master's thesis). Asian Institute of Technology, Thailand.

Verma, A.K., (2014). Socio-Economic Status of Cattle-Rearing Farmers in Golaghat District, Assam, India. The Asian Journal of Animal Science, 9 (2), 134-137.

\section{Ackowledgements}

We would like to thank Mr. P. Sivakumar, Director of Kaziranga National Park and Mr. A.M. Singh, Principal Chief Conservator of Forests (PCCF), Government of Assam for their incredible assistance and support throughout the study. Thanks to the villagers of the fringe areas for providing us with valuable inputs regarding their economic issues. Thanks to the Department of Zoology, Cotton University for their untiring support. We would also like to extend our thanks to the anonymous reviewers whose critical comments helped to substantially improve this manuscript. Lastly, heartfelt thanks go out to the Centre for Environment, Education and Economic Development (CEEED) for giving us excellent logistic support. 